\title{
Measuring and modeling coastal dune development in the Netherlands
}

\author{
A.V. de Groot ${ }^{1}$, S. de Vries ${ }^{2,3}$, J.G.S. Keijsers ${ }^{1}$, M.J.P.M. Riksen ${ }^{1}$, Q. Ye $^{2,3,4}$, A. Poortinga ${ }^{1}$, S. M Arens ${ }^{5}$, \\ L.M. Bochev-Van der Burgh ${ }^{6}$, K.M. Wijnberg ${ }^{6}$, J.L. Schretlen ${ }^{6}$, J.S.M. van Thiel de Vries ${ }^{2}$ \\ ${ }^{1}$ Land Degradation and Development Group, Wageningen University, P.O. Box 47, 6700 AA Wageningen, The Netherlands, \\ alma.degroot@wur.nl \\ ${ }^{2}$ Section of Hydraulic Engineering, Delft University of Technology, Delft, $2628 \mathrm{CN}$, The Netherlands \\ ${ }^{3}$ Deltares, P.O. Box 177, 2600 MH Delft, The Netherlands \\ ${ }^{4}$ UNESCO-IHE, Westvest 7, Delft, The Netherlands \\ ${ }^{5}$ Bureau for Beach and Dune Research, Iwan Kantemanplein 30, 1060 RM Amsterdam, The Netherlands \\ ${ }^{6}$ Water Engineering and Management, University of Twente, P.O. Box 217, 7500 AE, Enschede, The Netherlands
}

\begin{abstract}
In the past couple of years, new coastal-dune research has sprung up in the Netherlands. In this paper, we give an overview of ongoing projects at Wageningen UR, Deltares, TU Delft and UTwente: how these are connected and what type of questions are addressed. There is an increasing demand for the understanding and prediction of coastal dune dynamics, both on the short (year) and long (100 years) term. We approach this from a variety of angles: scientific and applied, short-term and long-term, data-driven and model-based, biotic and abiotic, process-based and rule-based, and focused on components and integrated. We give examples of results and end with a discussion of the benefits of this integrated approach.
\end{abstract}

\section{INTRODUCTION}

Coastal dunes are an important feature along the Dutch coast. They have a variety of functions, including coastal defense against flooding, recreation, drinking water supply and nature conservation. Coastal dunes develop through the interplay of sand transport by the wind and the sea, and vegetation growth (Figure 1) [Martinez and Psuty, 2008]. Large-scale sand supply is a strong driver for the type of dunes that will develop, but sea-level excursions, storm magnitude and frequency, wind and wave climate, beach width and shape, and dominant grain size all exert an influence on coastal dune formation on a variety of spatial and temporal scales [Sherman and Bauer, 1993; Short and Hesp, 1982]. Next to these complex interactions, man has strongly modified the coast by management practices such as dune reinforcements [Nordstrom and Arens, 1998].

Although coastal-dune research has already been done in the Netherlands for a long time, recently many new initiatives have started and new collaborations are explored. In this paper, we give an overview of ongoing projects that include the aeolian aspect of dune formation, how these are connected, and what type of questions are addressed. The recent interest in coastal dunes is inspired by both scientific questions and societal developments. From a scientific point of view, biogeomorphology and linkages between systems (e.g. underwater - above water) have become hot topics, and dunes are perfect examples of systems fitting within these concepts. Additionally, the dynamics of sediment transport continue to form a major scientific theme. From a management perspective, the impact of small and large coastal management practices such as dynamic coastal defense and the related (mega-) nourishments has gained much attention, raising questions on impacts and future developments. Further, global (climate) change is expected to significantly affect dynamic sedimentary coasts such as those with dunes.
Questions regarding coastal dunes thus range from the scale of seconds and meters, to the scale of the entire Dutch coast over a century. In the past, valuable research has been done on these issues, although that often addressed specific coastal locations, or only part of the system components, or concerned for arid rather than coastal systems. To increase our knowledge on coastal dunes, improve prediction capability under management scenarios (e.g. Sand Engine, long-term nourishment strategies) and climate change, and contribute to the daily engineering practice, a variety of projects has been developed. In the next sections we discuss these projects and preliminary results.

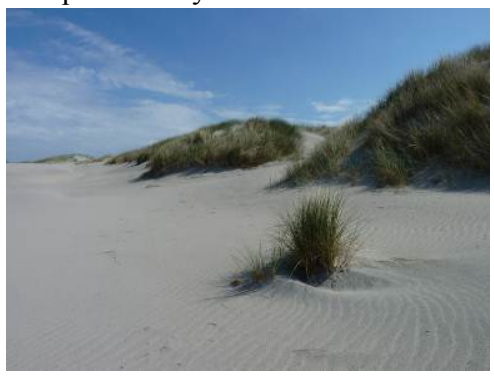

Figure 1. Dune formation on Ameland.

\section{FRAMEWORK}

The linking factor in the projects presented here is the aeolian processes building coastal dunes. Additionally, storm erosion and other hydrodynamic processes, management, and vegetation growth are included to various degrees. The positioning of the projects is given in Figure 2. The approaches can be divided into data-driven and model-driven, with Bayesian network analysis as hybrid in between. The combination of data and modeling is essential for understanding and predicting coastal dune formation. Data is used as basis for hypothesis and model development, including calibration and validation. Models, in their turn, give 
direction to data collection and further hypothesis development. A variety of model approaches is used, ranging from strongly process-based to behavior-oriented. In Bayesian networks, both field data and model-generated data can be used.

Temporal scales from hours up to a century are considered, related to spatial scales from metres to hundreds of kilometres. All studies have practical relevance, related to nourishment design, safety, and nature conservation. Their result can be used in daily management and engineering practice, for example within the context of EcoShape and Knowledge for Climate (Figure 2). We will describe the projects of Figure 2 in the next section, starting with data-driven projects and ending with modeling approaches.

\section{PROJECTS}

\section{Aeolian sediment transport on the beach}

Starting at the beach and at the smallest timescale, aeolian sediment transport is an important process in the development of dune geomorphology. In a beach environment, aeolian sediment transport is governed by saltating streamers. Although these have small temporal and spatial scales, their net effect is what drives aeolian sediment supply to the dunes. The saltation process is typically described on a small temporal $(\mathrm{sec})$ and spatial $(\mathrm{cm})$ domain, whereas total aeolian sediment transport is often studied on a much larger scale. Both approaches find difficulties in describing the process, because of the inherent spatial-temporal complexities of aeolian sediment transport. Results from the different scales are not easily inter-comparable, as data obtained from a small spatial or temporal domain cannot be easily extrapolated to a larger scale.

To gain more insight into the process of aeolian sediment transport and geomorphologic development, researchers from Wageningen University performed a field study at Ameland [Poortinga et al., in prep.]. They measured the meteorological conditions, sediment fluxes (Figure 3) and groundwater height spatially at the beach. A camera on the top of a dune acquired an image of the area every five minutes. The transport patterns under various wind regimes and other meteorological conditions were identified and compared with larger scale meteorological data and annually surveyed elevation transects (JARKUS) [Keijsers et al., in prep.]. Results can be found in Keijsers et al. (this issue). Later, these results will be used to build a short-term sediment transport model.

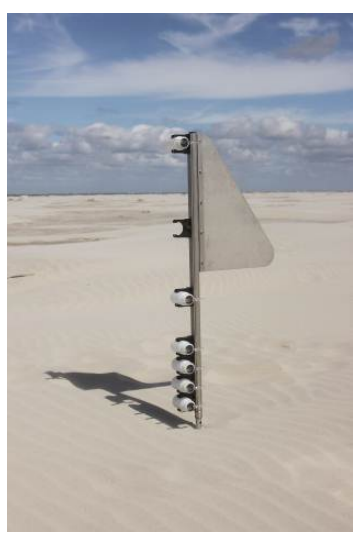

Figure 3. Sediment catcher on the beach of Ameland.

\section{Sediment transport from beach to hinterland}

Moving from the beach into the established dunes, increased atmospheric nitrogen deposition is perceived as a severe threat to dune ecosystems by reducing landscape dynamics and biodiversity. Wageningen University investigates if dynamic dune management can reduce these negative impacts on soil and vegetation, by creating the opportunity for sand to be transported in suspension far into the dune field during storms.

To get an idea of the quantity and range of this occasional suspension transport behind foredune, a pilot project was started on four locations along the Dutch coast: Ameland, Kwade Hoek, Voornsduin and Solleveld. So-called MDCO sediment traps (Marble Dust COllector) were installed to measure vertical

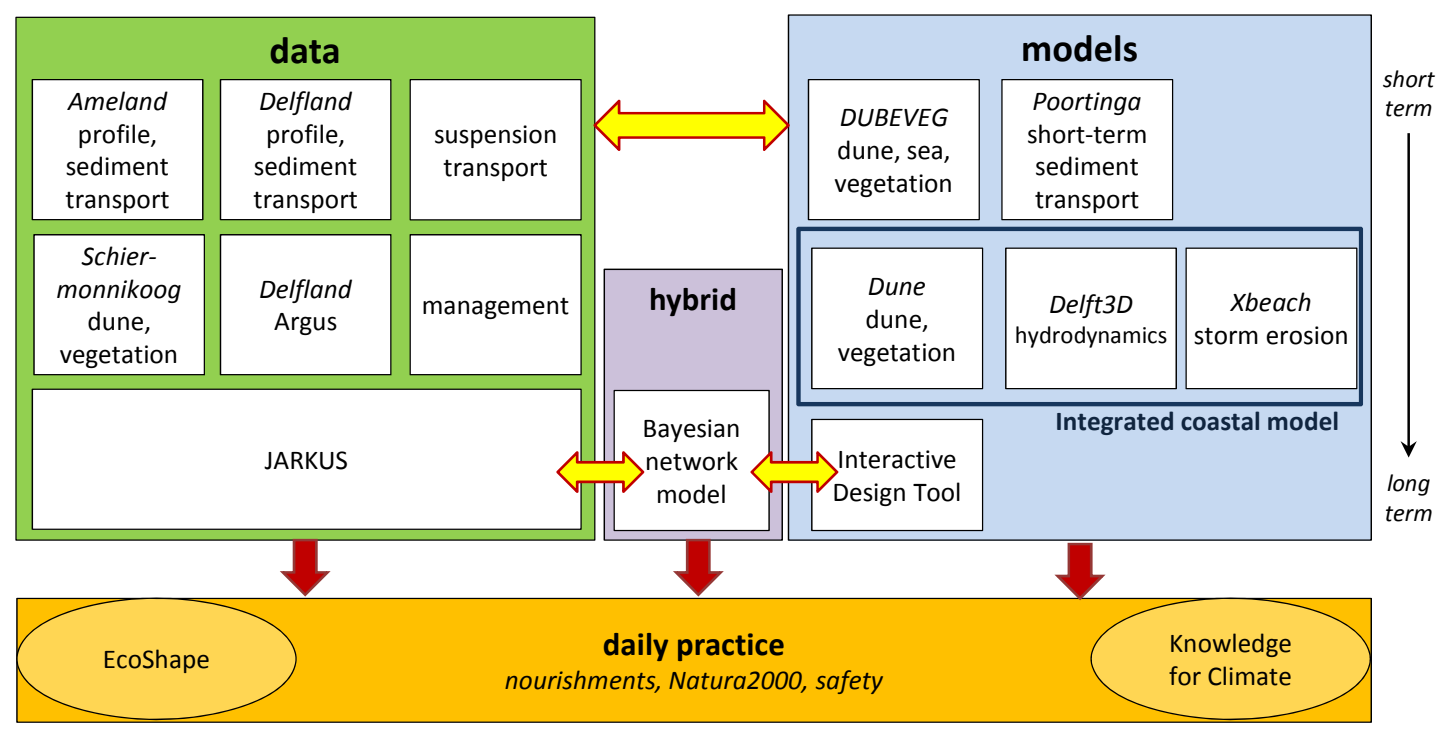

Figure 2. Framework of dune research, showing the data and models described in this paper. 
sediment deposition in transects running landwards from the foredune (Figure 4).

The first results show that sedimentation amount and pattern mainly depend on foredune characteristics, for instance related to the presence of dynamic dune management. Further research will identify the impact of this sedimentation on soil properties and vegetation.

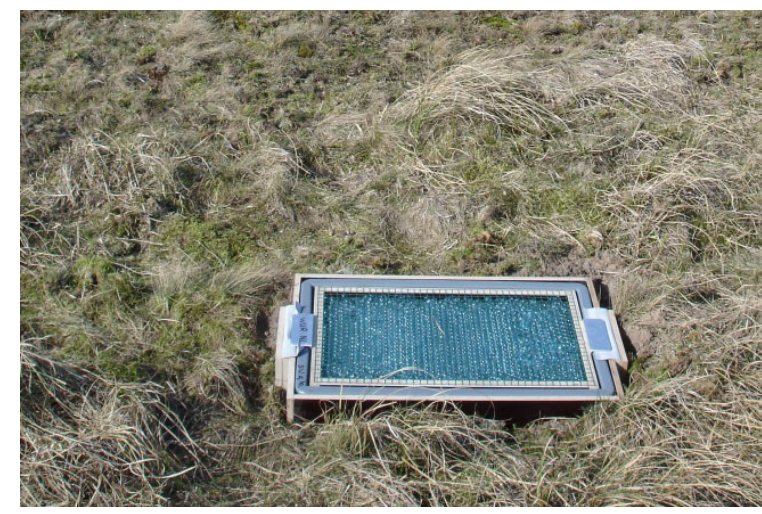

Figure 4. MDCO sediment trap for vertical sand deposition.

\section{Foredune volume}

On a larger timescale, foredune volume depends on the balance between dune erosion through wave attack and dune growth via aeolian transport. For the purpose of modeling foredune development over 10 to $100 \mathrm{y}$, Wageningen University tries to identify a limited set of factors that control the rate of sediment input to the dunes. Beach width is thought to be an important factor, as it controls sediment available for transport, wind fetch length and wave dissipation (limiting storm erosion). An analysis of 30 years of JARKUS beach and dune profile data of Ameland shows that this expected relationship between beach width and foredune growth is not evident at annual scale (Figure 5). Although strong erosion seems less frequent at beaches wider than $200 \mathrm{~m}$, growth rates are not necessarily higher at wider beaches.

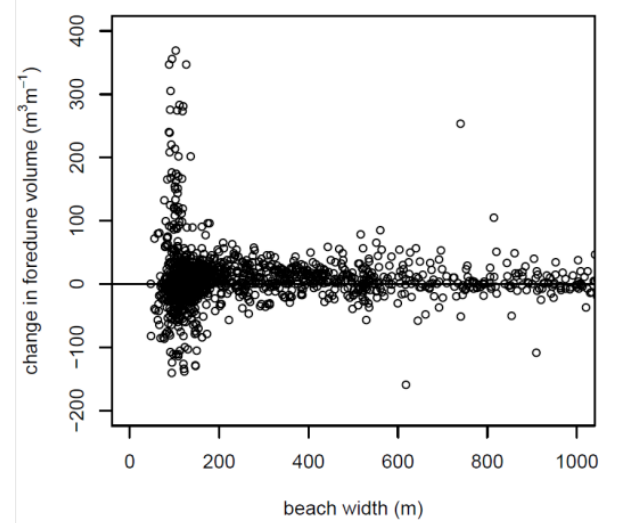

Figure 5. Annual changes in foredune volume and their corresponding beach widths at Ameland. Each point represents a single profile and year.

As beach width alone is not a good predictor of foredune growth at this location and time scale, further factors will be analyzed. The ultimate purpose is to design a long-term model to explore the possible effects of changing conditions on foredune development.

\section{Long-term foredune evolution under management interventions}

Recent work at the University of Twente also considers the understanding and prediction of aggregated scale evolution (10 year+) of foredunes, but focuses on the effects of management interventions on it. To analyze the relation between spatiotemporal variability in the cross-shore shape of the foredune and the applied management interventions, 49 year of JARKUS profiles along the Holland coast were analyzed [Bochev-van der Burgh et al., 2011; in press]. At the decadal scale, measures that were applied in response to erosional events and aimed at restoring the pre-erosion state (flattening dune scarps, erecting sand fences, planting marram grass), left less imprint on foredune shape than proactively applied measures that aimed at creating a buffer for erosion. A case study on Schiermonnikoog (Figure 6) showed that proactive intervention strategies tend to leave a larger imprint on the decadal scale than reactively applied measures, because they interfere with the foredune system at a higher hierarchical level.

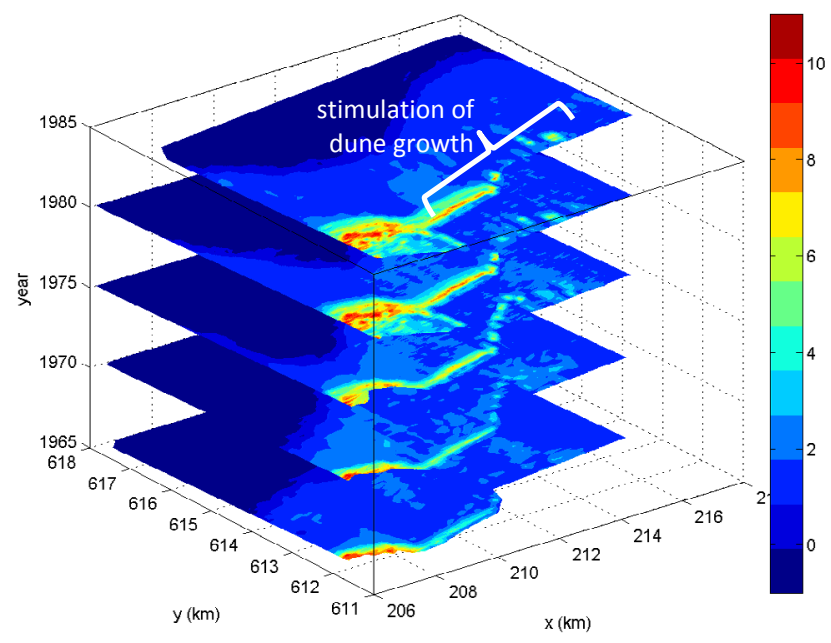

Figure 6. Topographic development at Schiermonnikoog from 1965 to 1985. The artificial stimulation of dune growth was only partially successful. Note: the cross-shore distance has been exaggerated 5 times; elevation in $m+N A P$.

For understanding morphological evolution beyond the process scale, such as the decadal scale evolution of managed foredunes, behavior-oriented modeling approaches seem promising. To develop aggregation rules, exploratory work has started to extract patterns in persistence of depositional areas around an artificially created dune, using Argus video imagery (Figure 7).

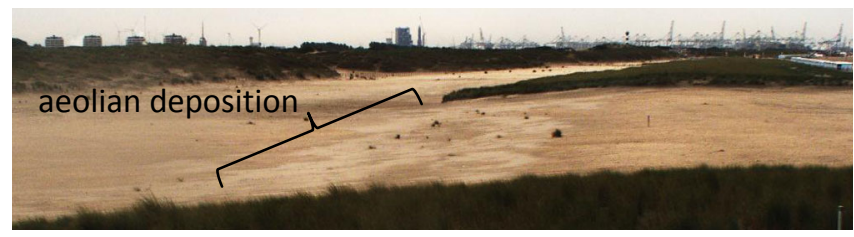

Figure 7. Argus image collected at Vlugtenburg beach (The Netherlands) showing depositional features at the landward side of a dune-like feature created by ground-moving equipment. 


\section{Foredune response to nourishments and changed management}

When further zooming in on management practices affecting foredune development, a notable change in Dutch coastal management policy was in 1990. Coastal erosion is now primarily combatted using sand nourishments, and foredunes are much less intensively managed. This management change has had two main effects on the foredune system. Firstly, the sediment budget of the foredune system has changed. Roughly $25 \%$ of the nourished volume is transferred into the dunes by aeolian processes [Arens et al., in prep.]. In many cases, the formerly negative sediment budget of the foredune changed into positive.

Secondly, the less intensive foredune management has resulted in an increase in the importance of natural processes, which is reflected in a more natural appearance of the foredunes. The northern part of the Holland coast shows increased dynamics, blowout development, increased inland sand transport (Figure 8). In contrast, the southern part mainly shows the development of new incipient foredunes in front of the former foredunes, leading to increased stabilization. The cause of this distinction between north and south lies probably in the interaction between shoreface, beach and foredunes. This issue needs to be resolved to 1) fully understand the response mechanisms to nourishments and 2) to be able to use nourishments more precisely as a management tool, meeting both coastal defense and nature requirements [Arens et al., in press].

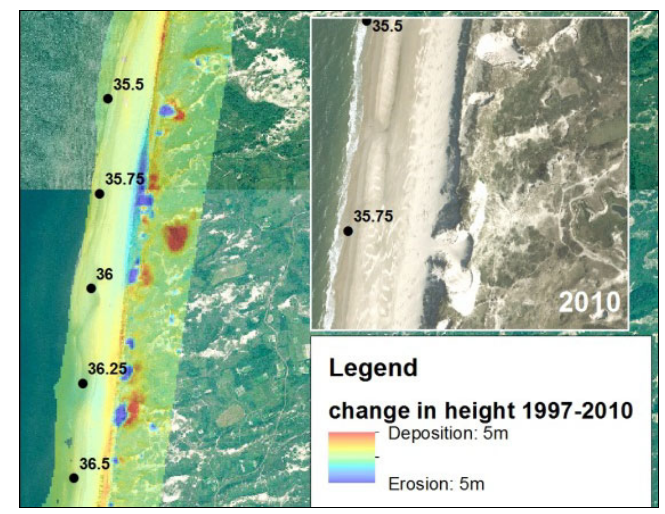

Figure 8. Blowouts in the foredunes of Noord-Holland, BergenEgmond evident from elevation changes (left) and aerial photographs (right).

\section{Bayesian network modeling}

The results from the above studies can be further exploited for evaluating existing models for dune development and forming a basis for new process formulations [De Vries et al., this issue]. An example of such application is a data-driven model in the form of a Bayesian network model. At Delft and Wageningen, such a model for the Holland Coast is being set up, starting with dune volume changes and beach slope (Figure 9). A Bayesian model uses the underlying data and specified connections between these data to provide a prediction of the expected value, its standard deviation and distribution based on conditions selected by the user. For instance, when selecting a specific beach slope and location, the network model gives the expected dune-volume change. The Bayesian network model can easily be extended towards other domains, such as nourishment locations or Wadden
Islands. Additional parameters (such as MKL volumes, foreshore slopes, marine conditions) can be added to fine-tune these databased predictions.

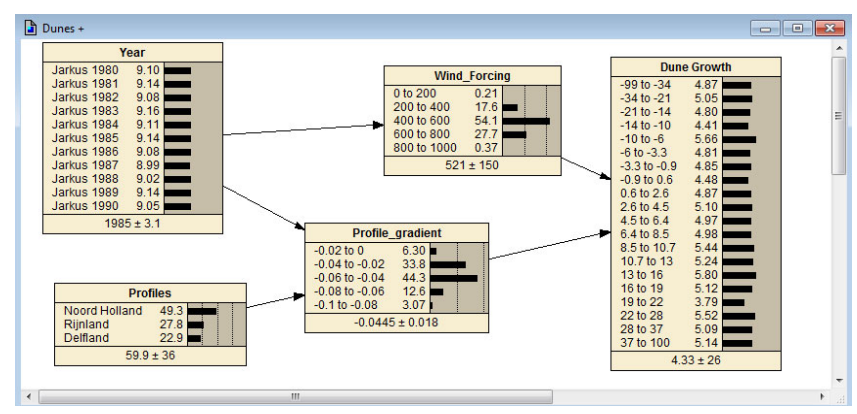

Figure 9. Example of the structure of a Bayesian network model. Selecting specific cases in the boxes on the left will give the corresponding distribution of the output variable on the right.

\section{Dunes in an Interactive Design Tool for the Holland coast}

A direct application of the findings of the above projects is a user-friendly, long-term model of the Holland Coast that is developed as part of the EcoShape program. This Interactive Design Tool allows stakeholders in the coastal zone to quickly see the effect of management interventions such as nourishments on the development of the coast on a timescale of 100 years. Google Earth is used as interface, and calculation time is kept as short as possible so that it can be used during stakeholder working sessions (Figure 10). As dunes are important features in how people perceive the coast, the model will be extended with a dune model that is currently under construction. The expertise of Wageningen UR, Deltares and TU Delft is combined to come to an efficient model design, where the challenge lies in predicting dune behavior with a minimum of input parameters and calculation time.

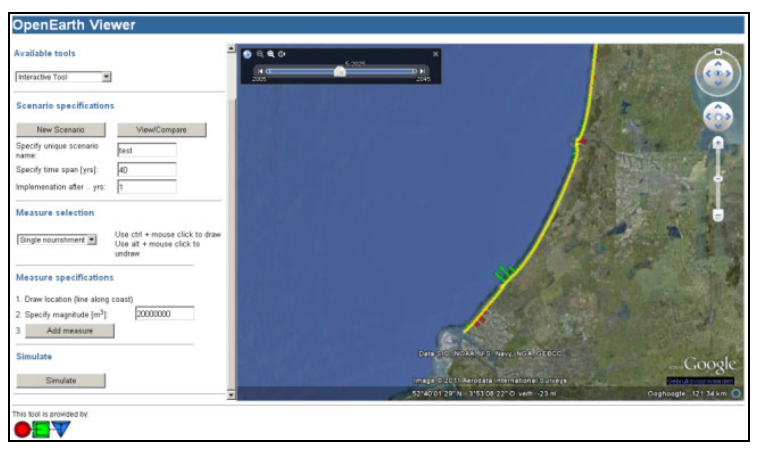

Figure 10. Screenshot of the Interactive Design Tool developed within Ecoshape.

\section{Ecological optimization of dynamic coastal defense}

Although dune formation, sea processes and vegetation development are closely interlinked, not much is known yet on the role of the vegetation. To study under which conditions ecologically valuable swales (NL: duinvalleien) develop, the DUBEVEG dune model was built at Wageningen University. This model integrates dune formation, vegetation growth, and sediment transport by the sea. The simulations show that vegetated swales develop if the beach is sufficiently wide to create accommodation 
space for new dune formation (Figure 11). After a new seaward dune has established, dune-slack vegetation establishes in the lowlying swale between the new dune and the previous foredune. The model is further used to study the impact of nourishments on the development of ephemeral swale [De Groot et al., in prep.] and will be validated using a GIS-based analysis of dunes and vegetation of the recently developed green beach on Schiermonnikoog.

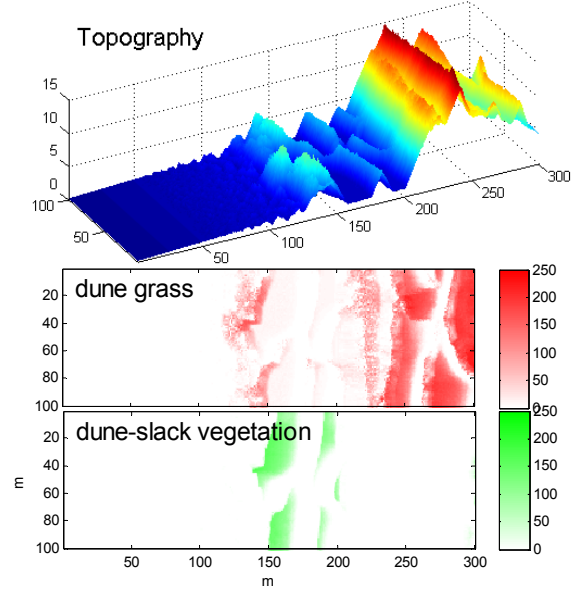

Figure 11. Simulated topography (upper panel) and vegetation biomass (lower panels) after 15 years, using the DUBEVEG model.

\section{A modeling shortcut: from data to engineering practice}

A second approach to integrate dune-forming factors in a modeling environment is undertaken at Deltares. To predict morphological changes at mega-nourishments such as the Sand Engine, an ecomorphological modeling approach is desired. The essence of ecomorphological modelling is to identify and represent the links between the hydrodynamic, morphodynamic, water quality and ecological processes involved on the appropriate spatial and temporal scales. This can be achieved by coupling various individual models. A method to do this is through ESMF (Earth System Modeling Framework), which is an open-source software framework for building and coupling various types of related models. The individual models are reformulated into smaller components, for instance I/O systems or computational kernels. The ESMF then provides toolkits to assemble the components into an integrated model system. Currently, in Delft an Integrated Coastal Model consisting of Delft3D-FLOW (hydrodynamics), Xbeach (storm events, low-frequency waves) and Dune (aeolian transport and dune formation) is under testing (Figure 2) [Baart et al., submitted]. It will eventually be applied to predict dune dynamics related to mega sand nourishments such as the Sand Engine.

\section{DISCUSSION AND CONCLUSIONS}

The Dutch coast is an excellent place to study dune formation. It has extensive stretches of dunes, with ample variation in dune form and the degree of management. Further, dunes fulfill important functions for society. There is an unparalleled historic coastal dataset available, mostly for free, of which especially
JARKUS is a well-used resource for studying long-term dune and coastal development. Its worth is again highlighted by its featuring in many of the studies of this paper.

The projects described in this paper started mostly independently. In parallel to the overarching NCK community, we found that there are large benefits in collaboration. Even if similar questions are addressed, universities and institutes all have their specific strengths and interests, so that research turns out to be complementary (cf. Figure 2). Advantages include: learning from each other's experience, standardizing methods, improve strategic planning, seeing the bigger perspective, having more opportunities for scientific discussion, and network building for young researchers. We further aim at keeping in contact with other Dutch groups investigating aspects of dune formation, such as OSL dating of storm erosion (Netherlands Centre for Luminescence dating, Delft), saltating streamers (UU), long-term coastal development and dune erosion (Deltares), and vegetation ecology (UvA).

The aim of the authors is Science for Impact: improving scientific understanding together with solving real-world problems from the management and engineering practice. The variety in approaches, timescales and spatial scales of the current studies (Figure 2) will provide a toolbox for doing so. The results of the presented projects are and will become available through scientific publications, reports, and the open knowledge databases of Deltares and EcoShape. In the scope of the Dutch Deltaprogramma and climate change, interest in coastal dunes continues, and new research proposals are actively being developed to continue and expand the current line of work.

\section{ACKNOWLEDGEMENTS}

The following funding has made our work possible: Knowledge for Climate (AdG and JK), EcoShape (AdG, SdV, KW, JS), WUR IPOP (AdG), OBN and Kustlijnzorg (BA), and LOICZ-ALW (LBvdB). Various colleagues at Deltares, TU Delft and Wageningen UR are thanked for their inspiring discussions. The authors greatly acknowledge the data made publicly available by KNMI and Rijkswaterstaat.

\section{REFERENCES}

Arens, S. M., L. Van der Valk, and S. P. Van Puijvelde (in prep.), Response of Dutch foredunes in changes in management.

Arens, S. M., Q. L. Slings, L. H. W. T. Geelen, and H. G. J. M. Van der Hagen (in press), Restoration of dune mobility in the Netherlands, in Restoration of coastal dunes, edited by M. L. Martinez, J. B. Gallego-Fernandez and P. Hesp, Springer.

Baart, F., J. Den Bieman, A. Luijendijk, J. A. Roelvink, M. J. F. Stive, J. S. M. Van Thiel de Vries, and Q. Ye (submitted), An integrated coastal model for aeolian and hydrodynamic sediment transport, in $E G U$ 2012, edited.

Bochev-van der Burgh, L. M., K. M. Wijnberg, and S. J. M. H. Hulscher (2011), Decadal-scale morphologic variability of managed coastal dunes, Coastal Engineering, 58(9), 927-936.

Bochev-van der Burgh, L. M., K. M. Wijnberg, and S. J. M. H. Hulscher (in press), Foredune management and foredune morphodynamics: A case study of the Netherlands' coast, Journal of Coastal Conservation. 
De Groot, A. V., F. Berendse, M. J. P. M. Riksen, A. C. W. Baas, P. A. Slim, H. F. Dobben, and L. Stroosnijder (in prep.), Modelling the effects of environmental factors and nourishments on coastal dune formation and associated vegetation development.

Keijsers, J. G. S., A. Poortinga, M. J. P. M. Riksen, and A. V. De Groot (in prep.), Aeolian sediment transport at the beach of Ameland (part II): foredune development.

Martínez, M. L., and N. P. Psuty (2008), Coastal Dunes: Ecology and Conservation, Springer-Verlag, Berlin, Heidelberg.

Nordstrom, K. F., and S. M. Arens (1998), The role of human actions in evolution and management of foredunes in The Netherlands and New Jersey, USA, Journal of Coastal Conservation, 4(2), 169-180.

Poortinga, A., J. G. S. Keijsers, S. M. Visser, M. J. P. M. Riksen, and A. C. W. Baas (in prep.), Aeolian sediment transport at the beach of Ameland (part I): measuring aeolian sediment fluxes.

Sherman, D. J., and B. O. Bauer (1993), Dynamics of beach-dune systems, Progress in Physical Geography, 17(4), 413-447.

Short, A. D., and P. A. Hesp (1982), Wave, beach and dune interactions in southeastern Australia, Marine Geology, 48(3-4), 259-284. 